\title{
Descriptive Epidemiology of Physical Activity Levels and Patterns in New Zealanders in Advanced Age
}

\author{
Casey Mace, Ngaire Kerse, Ralph Maddison, Timothy Olds, Santosh Jatrana, Carol Wham, \\ Mere Kepa, Anna Rolleston, Ruth Teh, and Joanna Broad
}

\begin{abstract}
Background: Little is known about the physical activity levels and behaviors of advanced age New Zealanders. Methods: A cross-sectional analysis of data from Life and Living in Advanced Age: A Cohort Study in New Zealand (LiLACS NZ), Te Puāwaitanga O Nga Tapuwae Kia ora Tonu, measures of physical activity (PASE) $(n=664$, aged 80-90 [ $n=254$, Māori, aged 82.5(2), $n=410$ non-Māori, aged 85(.5)]) was conducted to determine physical activity level (PAL). A substudy $(n=45)$ was conducted to attain detailed information about PAL and behaviors via the Multimedia Activity Recall for Children and Adults (MARCA) and accelerometry. The main study was analyzed by sex for Māori and non-Māori. Results: Men consistently had higher levels of physical activity than women for all physical activity measures. Sex was significant for different domains of activity.
\end{abstract}

Keywords: aging, advanced age, physical activity

In New Zealand, it is estimated that the proportion of those aged over 85 years (currently $1 \%$ ) will comprise $6 \%$ by 2050 (Hayman et al., 2012). Health and disability expenditure is highest for this age group and those over 85 years consume half of all expenditures on residential care services in New Zealand. This has serious implications in terms of health delivery services, as older people have a higher prevalence of disease and disability than other populations (Annear, 2008). Demographic changes for Māori, indigenous people of New Zealand, are happening faster than for non-Māori in New Zealand, and the Treaty of Waitangi stipulates equal attention to health and well being for Māori. Many health problems that are experienced later in life are preventable and have been shown to be associated with a less physically active lifestyle associated with growing older (Annear, 2008). A focus on preventing disease, disability, and dependency in the oldest old could ease the demand for care and resources as well as improve the quality of life for those living in advanced age.

Incidental activities such as housework, washing the car, or gardening are a sign of independence and comprise much of the physical activity done by older people (Shephard, 2002). Aside from the benefits of improved fitness and positive physical health, benefits to mental health and health-related quality of life are related to physical activity levels (Conn, Hafdahl, \& Brown, 2009; Rejeski

Mace is with the Department of Health, Educational Administration and Movement Studies, Central Washington University, Ellensburg, WA. Kerse, Kepa, and Teh are with the Department of General Practice and Primary Care, University of Auckland, New Zealand. Maddison is with the National Institute for Health Innovation, University of Auckland, New Zealand. Olds is with the Alliance for Research in Exercise, Nutrition and Activity (ARENA), Sansom Institute for Health Research, University of South Australia, Adelaide, Australia. Jatrana is with the Alfred Deakin Research Institute, Deakin University, Wollongong, Australia. Wham is with the Institute of Food, Nutrition \& Human Health, Massey University, Auckland, New Zealand. Rolleston is with the Department of Medicine, University of Auckland, New Zealand. Broad is with the Freemasons Department of Geriatric Medicine, University of Auckland, Auckland, New Zealand. Address author correspondence to Casey Mace at cjmace@indiana.edu.
\& Mihalko, 2001). Physical activity data from the 2007/08 ActiveNZ survey (Sport and Recreation New Zealand, 2008) showed that $65 \%$ of adults aged 65 years and older did not meet the guidelines for regular physical activity (at least 150 min of physical activity per week). Nearly a quarter (24\%) of adults aged 65 years and over reported that they did little or no activity during a typical week, making this the most inactive group in the survey (Marc, Raue, \& Bruce, 2008; SPARC, 2007/2008). These low levels of physical activity may have implications for how older people age.

Given the benefits of regular physical activity, guidelines exist in many countries as part of goals to increase the overall population health (World Health Organization [WHO], 2009). These guidelines are often general and do not necessarily target the older person. The World Health Organization (WHO) has developed physical activity and aging material for older adults, defined as 60 years and older. There are no specific guidelines for those aged over 80 years. The New Zealand Ministry of Health (NZMOH) has identified specific benefits for older adults who participate in physical activity in their online series titled "Guidelines to Help Older New Zealanders Stay Healthy" (NZMOH, 2013). However, data regarding physical activity levels in both Māori and non-Māori populations of advanced age in New Zealand are lacking. Māori are the indigenous people of New Zealand and, for a variety of reasons, suffer poorer health outcomes compared with non-Māori. The indigenous cohort can also expect to live a shorter life (Tobias \& Cheung, 2003). In the research study, Te Puāwaitanga o Nga Tapuwae Kia Ora Tonu, or, Life and Living in Advanced Age: A Cohort Study in New Zealand (LiLACS NZ), the Māori cohort of oldest old could be described as an elite group because of their longevity relative to previous generations of Māori. This group has been identified as physically active but more information about their activity is needed.

\section{Aims}

The aim of this study is to describe patterns and levels of physical activity in Māori and non-Māori New Zealanders in advanced age using multiple measures. This study also aims to contrast physical activity in advanced age by sex. The main study assesses the baseline cohort from a longitudinal study using a widely validated measure 
of physical activity, while a substudy was conducted to gather more precise details about the various domains of physical activity in which this group participates by using accelerometry and a detailed time use measure, the Multimedia Activity Recall for Children and Adults (MARCA), to produce detailed descriptions of time use.

\section{Methods}

\section{Study Design}

Main Study. LiLACS NZ (Hayman et al., 2012) commenced in 2010 and is a longitudinal cohort study with a focus on the health and well being of adults living in advanced age, with a planned continuation of five years. Participants were identified through the New Zealand electoral roll, Hauora (Māori Health Services), and community outreach. Exhaustive sampling was attempted, where an attempt to contact and enroll every eligible person was made. Participants were in advanced age (non-Māori aged 85 and Māori aged 80-90 years during the recruitment period [March 2010-March 2011]) who lived in the defined district health boundaries in the North Island of New Zealand and understood English and/or Te Reo (the language of Māori). In-depth details of engagement and recruitment of this cohort study are outlined in a previous publication (Dyall et al., 2013).

Substudy Design. An observational substudy ( $n=45)$ was conducted to validate a self-report use of time measure, the MARCA, against accelerometers, and provide a detailed description of activity patterns. Participants who completed the Physical Activity Scale for the Elderly (PASE) (Washburn, Smith, Jette, \& Jamney, 1993) during the LiLACS NZ baseline interview were eligible to participate in the substudy. To get a representative distribution of participants, we recruited equal numbers of participants based on their PASE scores, as well as equal numbers of men and women. Nearly an even number of men $(n=23)$ and women $(n=22)$ were recruited into the substudy. There were $(n=12)$ Māori and $(n=$ 33) non- Māori.

Exclusion criteria for the substudy included cognitive impairment, living in residential care, English as a second language (other than those speaking Te Reo), and living outside of the target area. Individuals in the LiLACS NZ study were contacted and given information about the MARCA study. Participants were given at least two weeks to consider participation before enrolling. Written informed consent was obtained and the study was approved by the Upper South A Regional Ethics Committee (URA/10/08/063).

\section{Measures}

Sociodemographics (Main Study and Substudy). Trained interviewers used standardized techniques to complete intervieweradministered questionnaires covering a range of psychosocial health measures. Full sociodemographic details of the LiLACS NZ study are published elsewhere (Teh et al., 2014). However, information regarding sex, ethnicity, marital status, education levels, financial status, disability, depressive symptoms, and functional status are presented for the main study and the substudy. Demographic data were measured by standard census questions from the Ministry of Health. Disability was measured by a dichotomous (yes/no) selfreport measure of whether an individual had a disability lasting six months or more. The Geriatric Depression Scale (GDS) (de Craen, Heeren, \& Gussekloo, 2003) was used to measure number of depressive symptoms, with a score of four or more suggesting significant depressive symptoms associated with the diagnosis of depression.
Low functional status was measured by the Nottingham Extended Activities of Daily Living Scale (NEADL) (Nouri \& Lincoln, 1987), with individual scoring lower than 17 on the NEADL classified as at risk for having low functional status.

PASE (Main Study). The PASE is a self-reported physical activity measure developed for adults over the age of 65 that takes about 5-10 $\mathrm{min}$ to complete, is reliable and valid, and is easily scored (Washburn et al., 1993). It was chosen because of its wide application in the study of older people and because of its brevity and convenience. The PASE collects information on a seven-day recall period and can yield information about time spent in various categories of activity such as household, leisure, and occupational activities. Household activities include light and heavy housework, home repairs, lawn care, gardening, and caring for another person, all of which are important to the lives of older people. Household questions only asked whether the individual has participated in any activity of this type during the past week. Occupational activities included both paid and unpaid work. This area of questioning asked respondents whether they engaged in any occupational activity during the past week, whether it was paid, how many hours they worked, and the level of physicality to the work. Leisure activity included any activity that is undertaken for recreation, fitness, or pleasure. Respondents were asked to report the type of activity that they participated in (sitting, walking, light, moderate, strenuous, strength/endurance) along with the frequency and duration of such activities. The total PASE score was derived by multiplying the duration of each activity (hours/week) or participation (yes/no) by the empirically derived item weights and summing over all activities. Scores range from 0-361, and the continuous scoring can be useful in correlations to other continuous measures (Washburn et al., 1993).

\section{Substudy Measures}

Multimedia Activity Recall for Children and Adults. The MARCA is a computerized 24-hr recall use of time tool that has been validated for use in advanced age people in New Zealand. It has demonstrated excellent test-retest reliability $(\mathrm{ICC}=0.99)$ and good convergent validity (rho $=0.59$ ) for measures of physical activity level (PAL) compared with accelerometry in advanced age New Zealanders (Mace, Maddison, Olds, \& Kerse, 2014). A key design feature of the MARCA is the day reconstruction methodology in which a person recalls the previous day from beginning to end, which is proposed to enhance recall (Banda et al., 2010; Harada, Chiu, King, \& Stewart, 2001). Using the MARCA, participants recall their previous day in periods as short as $5 \mathrm{~min}$. Use of time is anchored around common daily activities such as waking up, eating meals, and going to bed (Gomersall, Olds, \& Ridley, 2011). Participants choose from a menu of about 550 activities, grouped under seven main categories (inactivity, transport, sport/recreation, occupation, self-care, home activities, and other). Each activity is assigned a compendium-based metabolic equivalent of a task (MET) value to estimate intensity and energy expenditure (Gomersall et al., 2011; Ridley, Ainsworth, \& Olds, 2008). An estimate of average daily PAL at the end of the interview is calculated. Furthermore, the MARCA can provide a list of activities in sequence along with the duration, frequency, intensity, and type of activities that occurred. Depending on the participant, the MARCA takes around $15 \mathrm{~min}$ on average to complete.

ActiGraph Accelerometer. Participants were asked to wear an ActiGraph Accelerometer (Model AM7164-2, Pensacola, FL) upon their right hip for seven consecutive days during waking hours. Participants were instructed to not wear accelerometers during 
water-based activities. Accelerometer data were downloaded onto a computer and processed into counts: total daily activity counts, average daily activity counts, and average counts per minute. In the current study, a valid accelerometer minute was defined as a recorded minute that did not fall into a sequence of $\geq 60 \mathrm{~min}$ of zero activity counts (Mâsse et al., 1998). A valid accelerometer day was defined as a recorded day that had a minimum of 600 valid minutes (i.e., $10 \mathrm{hr}$ ). All nonvalid days and minutes were removed from the accelerometer data before analysis.

\section{Data Analysis}

Demographics. Demographic data including marital status, education level, and financial status are summarized using descriptive statistics.

PASE (Main Study). The total PASE score as well as the individual measures that construct the PASE are presented. Participants who had other missing data for the main study but had variables for PASE were included in the frequency analysis. Participants who had a missing total PASE score were excluded from analyses. PASE scores were averaged for each sex within ethnic groups. Each individual dimension of the PASE score was analyzed for detail about the frequency, duration, and intensity of activities that were reported. Independent $t$ tests were performed on the total PASE score and the individual PASE constructs measuring the household, occupational, and leisure activities undertaken by men and women within each ethnic group to determine whether activities varied by sex. In presenting our results, we have taken the approach of Rothman (1990), where he argues that it is better to describe all the significance tests performed and allow the reader to reach a reasonable conclusion than to overadjust for type I error, which automatically increases the likelihood of a type II error.

Multimedia Activity Recall for Children and Adults (Substudy). MARCA data were processed using the analytical module, whereby profiles were scanned for abnormalities, including individual files with a PAL $<1.1$ METs, less than 10 activities reported, less than four days of data, and having missing data within the 1,440 min reported. Abnormal data were not included in the analyses.

The processed data included the following outcomes of physical activity: average daily PAL, average daily energy expenditure or the METs, time spent in nonsedentary physical activity (NSPA), time spent in moderate to vigorous activity, and descriptive information about time spent in different activities, as well as the time of day that activities occurred. Categories such as activities of daily living (ADL) were created with the appropriate activities included: home maintenance, gardening, walking, recreation, and exercise. It was important to report these domains of activity as they are very important to the daily lives of older adults (Kempen, Myers, \& Powell, 1995). The processed MARCA data files provided the amount of time spent in individual activities as well as the relative intensity where applicable. Activities were able to be grouped into different categories depending on the function or purpose of the activity.

Activities grouped in ADL (according to the NEADL) included any activity pertaining to self-care (walking, bathing, toileting, grooming). Also derived from the NEADL were activities included in instrumental activities of daily living (IADL), referring to any activity pertaining to maintaining independence or requiring interaction with the outside environment or community (shopping, cooking, home finance, driving, laundry, cleaning). Home maintenance included any activities that pertained to maintaining one's own residence that was more than ordinary house cleaning (cleaning gutters, mowing the lawn). Gardening included any activity that contributed to the growing or upkeep of a garden (watering, weeding, planting, digging). Walking activities included incidental and purposive walking. Recreation included sport and leisure activities, and exercise included activities for the purpose of improved fitness such as aerobics, weight training, or swimming. The average time spent in each domain of activity for men and women was analyzed with independent $t$ tests to determine sex difference in time use.

Accelerometer (Substudy). Accelerometer data were downloaded onto a computer and processed into counts: total daily activity counts, average daily activity counts, and average counts per minute. In the current study, a valid accelerometer minute was defined as a recorded minute that did not fall into a sequence of $\geq$ 60 min of zero activity counts (Mâsse et al., 1998). A valid accelerometer day was defined as a recorded day that had a minimum of 600 valid minutes (i.e., $10 \mathrm{hr}$ ). All nonvalid days and minutes were removed from the accelerometer data before analysis.

\section{Results}

Table 1 presents the characteristics of the main study (LiLACS NZ) sample and the MARCA substudy sample. The LiLACS sample had two different age groups ( $n=664$, comprising 254 Māori aged 80-90 mean age 82.5[2] and 410 non-Māori aged 85[.5]). The MARCA group were all within the 85 year age group $(n=48)$. However, there was only valid accelerometer data from $(n=45)$ participants.

\section{Physical Activity Levels and Patterns in Advanced Age People}

Total PASE scores along with household, occupational, and leisure activities were determined by the constructs of the PASE.

Average PASE Scores. Māori women had lower PASE scores ( $M$ $=101.41, S D=73.34)$ than Māori men $(M=130.78, S D=93.52)$ $(t[248]=2.67, p=.010)$. Non-Māori women had lower PASE scores $(M=85.77, S D=54.57)$ than non-Māori men $(M=116.62, S D=$ 73.57) $(t[403]=2.26 . p=.006)$. Overall men had higher levels of physical activity than women. Māori were approximately 2.5 years younger than non-Māori. There was no significant differences between activity levels by ethnicity when age was controlled.

Levels of Household and Occupational Physical Activity. Table 2 presents the engagement in household and leisure activity by both men and women, Māori and non-Māori. Significant differences between men and women in each sample group are noted in the women's column.

Māori women and men had statistically significant differences in all areas of household activities aside from gardening. Māori women reported higher rates of light housework $(t[249]=1.49, p<$ .001) than Māori men. However, Māori women reported less heavy housework $(t[249]=-1.48, p=.01)$, home repairs $(t[249]=-2.93$, $p<.001)$, yard/lawn work $(t[249]=-4.53, p<.001)$, and caring for others $(t[249]=-2.48, p<.001)$ than Māori men. There was not a statistically significant difference between occupational activities (mostly volunteer) between Māori women (31\%) and men (24\%).

Non-Māori women engaged in more light housework than men $(t[195]=2.16, p<.001)$. Less non-Māori women engaged in heavy housework $(t[403]=1.66, p=.03)$, home repairs $(t[403]=-3.05, p<$ $.001)$, lawn care/yard work $(t[400]=-5.05, p<001)$, outdoor gardening $(t[402]=-1.30, p=.03)$, and caring for another person $(t[403]$ $=-1.06, p=.01$ ) than non-Māori men. However more non-Māori women engaged in occupational activities (most of which were volunteer based $)$ than their male counterparts $(t[195]=2.16 . p<.001)$. 
Table 1 Demographic Characteristics of Main Study and Substudies

\begin{tabular}{|c|c|c|c|c|}
\hline \multirow[b]{2}{*}{ Sample Characteristics } & \multicolumn{2}{|c|}{$\begin{array}{l}\text { Main (LiLACS NZ) Study } \\
(n=664) \text { (aged 80-90) }\end{array}$} & \multicolumn{2}{|c|}{$\begin{array}{c}\text { MARCA Substudy } \\
(n=48) \text { (age 85) }\end{array}$} \\
\hline & $n$ & $\%$ & $n$ & $\%$ \\
\hline \multicolumn{5}{|l|}{ Sex } \\
\hline Women & 372 & 56 & 24 & 50 \\
\hline Men & 292 & 44 & 24 & 50 \\
\hline \multicolumn{5}{|l|}{ Ethnicity } \\
\hline Māori & 254 & 38 & 12 & 25 \\
\hline Non-Māori & 410 & 62 & 36 & 75 \\
\hline \multicolumn{5}{|l|}{ Marital status } \\
\hline Married or partnered & 254 & 40 & 26 & 54 \\
\hline Widow/widower & 340 & 52 & 18 & 38 \\
\hline Separated/divorced & 36 & 5 & 3 & 6 \\
\hline Never partnered & 18 & 3 & 1 & 2 \\
\hline \multicolumn{5}{|l|}{ Education level } \\
\hline Primary or no schooling & 135 & 21 & 8 & 16 \\
\hline Secondary education/trade & 434 & 66 & 31 & 65 \\
\hline Tertiary education & 88 & 13 & 9 & 19 \\
\hline \multicolumn{5}{|l|}{ Financial status } \\
\hline Just enough to get by & 167 & 25 & 11 & 23 \\
\hline Comfortable & 488 & 75 & 37 & 77 \\
\hline \multicolumn{5}{|l|}{ Presence of disability } \\
\hline Yes & 339 & 51 & 25 & 52 \\
\hline No & 325 & 49 & 23 & 48 \\
\hline \multicolumn{5}{|l|}{$>4$ depressive symptoms } \\
\hline Yes & 53 & 8 & 3 & 6 \\
\hline No & 604 & 92 & 45 & 94 \\
\hline \multicolumn{5}{|c|}{ Low functional status ( $<17$ NEADL) } \\
\hline Yes & 173 & 26 & 3 & 6 \\
\hline No & 491 & 74 & 45 & 94 \\
\hline
\end{tabular}

Note . Presence of depression = disability measured by self-report, indicated by Geriatric Depression Score. Low functional status $=$ low score on Nottingham Extended Activities of Daily Living Scale (NEADL). LiLACS NZ $=$ Life and Living in Advanced Age: A Cohort study in New Zealand; MARCA = Multimedia Activity Recall for Children and Adults.

For non-Māori men and women who did engage in occupational activities, there was no significant difference between the time spent in these activities or the level of physical activity required for the work. It should be noted that almost all of the occupational activities undertaken by these men and women $(>97 \%)$ were volunteer positions and they spent around 6-7 hr per week on average engaged in this activity.

Levels of Leisure-Based Physical Activity: Frequency. The following section presents the frequency of leisure time activity of advanced age adults (refer to Figure 1).

According to the PASE, Māori women and men had significantly different frequencies for participation in sitting activities $(t[250]=-0.90, p=.01)$, strenuous activities $(t[246]=-2.11, p<$ $.001)$ ), and participation in fitness (strength, endurance) activities $(t[244]=1.54, p=.01)$.
Non-Māori women and men did not have a significant difference for the frequency of engaging in sedentary activity, walking, light activity, or strength or endurance training during the previous week. However, there was a significant difference between the frequency of engaging in moderate $(t[402]=-2.70, p<.001)$ and strenuous $(t[399]=-2.72, p<.001)$ activities for non-Māori women and men.

Levels of Leisure Time Activity: Duration. The average time spent in various leisure-based physical activities according to the PASE are shown in Figure 2.

There were no significant differences between the duration of leisure activities for Māori women and men. For non-Māori women and men there were significant differences between the time spent in walking activities $(t[331]=-1.39, p<.001)$, light activities $(t[224]$ $=-3.11, p=.01)$, and strenuous activities $(t[27]=-1.95, p=.05)$. 
Table 2 Engagement in Household and Occupational Physical Activity by Advanced Age New Zealanders

\begin{tabular}{|c|c|c|c|c|}
\hline & $\begin{array}{l}\text { Māori Women } \\
(n=149)\end{array}$ & $\begin{array}{c}\text { Māori Men } \\
(n=101)\end{array}$ & $\begin{array}{c}\text { Non-Māori Women } \\
(n=217)\end{array}$ & $\begin{array}{c}\begin{array}{c}\text { Non-Māori Men } \\
(n=188)\end{array} \\
\end{array}$ \\
\hline & Yes & Yes & Yes & Yes \\
\hline Engagement Measure & $n(\%)$ & $n(\%)$ & $n(\%)$ & $n(\%)$ \\
\hline \multicolumn{5}{|l|}{ During the past 7 days did you engage in any. . } \\
\hline Light housework & $138(93)^{* *}$ & $89(87)$ & $201(93)^{* *}$ & $165(88)$ \\
\hline Heavy housework & $78(52)^{*}$ & $63(62)$ & $84(39) *$ & $101(54)$ \\
\hline Home repairs & $11(7)^{* *}$ & $20(20)$ & $7(3) * *$ & $48(25)$ \\
\hline Lawn care/yard work & $36(24)^{* *}$ & $52(51)$ & $49(23)^{* *}$ & $86(46)$ \\
\hline Outdoor gardening & $80(54)$ & $59(58)$ & $109(51)^{*}$ & $107(57)$ \\
\hline Caring for another & $28(19) * *$ & $33(32)$ & $34(16)^{*}$ & $37(20)$ \\
\hline \multicolumn{5}{|c|}{ Over the past 7 days did you work for pay or as a volunteer? } \\
\hline Yes & $24(31)$ & $25(34)$ & $44(47)^{* *}$ & $35(34)$ \\
\hline No & $53(69)$ & $49(66)$ & $49(53)$ & $69(66)$ \\
\hline Average hours of work/volunteering, $M(S D)$ & $6.7 \pm 8.9$ & $8.1 \pm 11.0$ & $6.5 \pm 7.2$ & $6.9 \pm 12.3$ \\
\hline \multicolumn{5}{|l|}{ Level of physical activity of work } \\
\hline Mostly sitting & $9(30)$ & $7(35)$ & $19(39)$ & $10(25)$ \\
\hline Sitting or standing with some walking & $12(40)$ & $6(30)$ & $19(39)$ & $20(50)$ \\
\hline Walking with some handling/heavy lifting & $9(30)$ & $7(35)$ & $11(22)$ & $10(25)$ \\
\hline
\end{tabular}

Note. $\% *=p<.05$ or $\% * *=p<.001$ on female percentages denote significant difference between men and women, Measured by a construct of PASE (Physical Activity Scale for the Elderly).

\section{The Substudy Results}

Table 1 presents demographic information for those $(24$ male, 24 female) who participated in the substudy. Table 3 shows the MARCA and accelerometry levels of activity for the sample.

Table 3 presents the physical activity characteristics of the subsample collectively and by sex. The MARCA measures for daily average PAL, and daily average time spent in NSPA are presented. Also displayed are the average daily activity counts and the average count per minute measured by the accelerometer (Figure 3 ).

Men had a higher average PAL $(p<.05)$ but there were not significant differences between men and women for the measure of NSPA or accelerometer data (Table 3).

Descriptive Patterns of Time Use. The activity patterns based on average counts per minute on accelerometers for older adults are illustrated below. Individuals were not instructed to wear the accelerometers during bedtime, therefore only the hours between 6:00 a.m. and 12:00 a.m. are displayed. Figure 3 illustrates the overall daily average activity count patterns for older adult men and women. Patterns of high and low activity emerged; therefore, a further analysis of the MARCA data were conducted to better understand the type of activities undertaken during periods of high and low activity.

On average, advanced age men had greater periods of more intense activity in the morning from about 9 a.m. until noon and a dip in activity at noon followed by another bout of moderate intensity activity in the afternoon from about 1:30-3:30 p.m., which eventually tapered off. Date- and time-matched analysis of the MARCA data revealed that, during the morning bout of activity (9:00 a.m.-noon), the most common activities engaged in were: chores (inside and outside), which comprised tidying up around the home and outdoor yard and lawn work on average for about an hour; and gardening, which collectively accounted for 23 min per day. Doing the shopping accounted for approximately $12 \mathrm{~min}$ of activity during that time. During the afternoon bout, men continued to work on chores, including indoor and outdoor work (40 min) and gardening (20 min), spending on average less time in each category than in the morning. Sedentary activities during the first half of the day included reading, social visits, talking on the phone, and quiet time, which each accounted on average between 20-30 min of time for older men (Figure 3).

Women tended to sustain a lower intensity of activity over a longer period of time and performed light activity throughout the day. Again, date- and time-matched analysis showed that morning activities consisted mainly of household chores such as tidying up around the house indoors (about 60 min per day) and another 15 min on average were spent on outside chores, while they did about 19 min of gardening on average during this time. Women spent time communicating and socializing during the inactive bout (12:30 p.m. $-1: 30$ p.m.). Women spent about half an hour socializing with others or communicating on the telephone or in person. During the next period of active time, women were engaged in more chore time (34 more minutes on average) and a bit more gardening (about $8 \mathrm{~min}$ on average) (Figure 3).

Self-Reported Domains of Time Use from MARCA. Older adults reported spending $19 \%$ of their 24 -hr day moving, $41 \%$ in sedentary (sitting) activities, and $40 \%$ sleeping. There was little difference between men and women $( \pm 1 \%)$ for average time spent in each domain of activity.

Activity domains expanded under sitting and moving gave more information about activities in which older adults engage (presented in Table 4), which demonstrates the average time (min) spent in various activities by sex.

Older men and women spent approximately the same amount of time sleeping ( $9.5 \mathrm{hr})$, sitting (10 hr), and moving (4.5 hr). However, within these domains of activity, men and women spent their time 


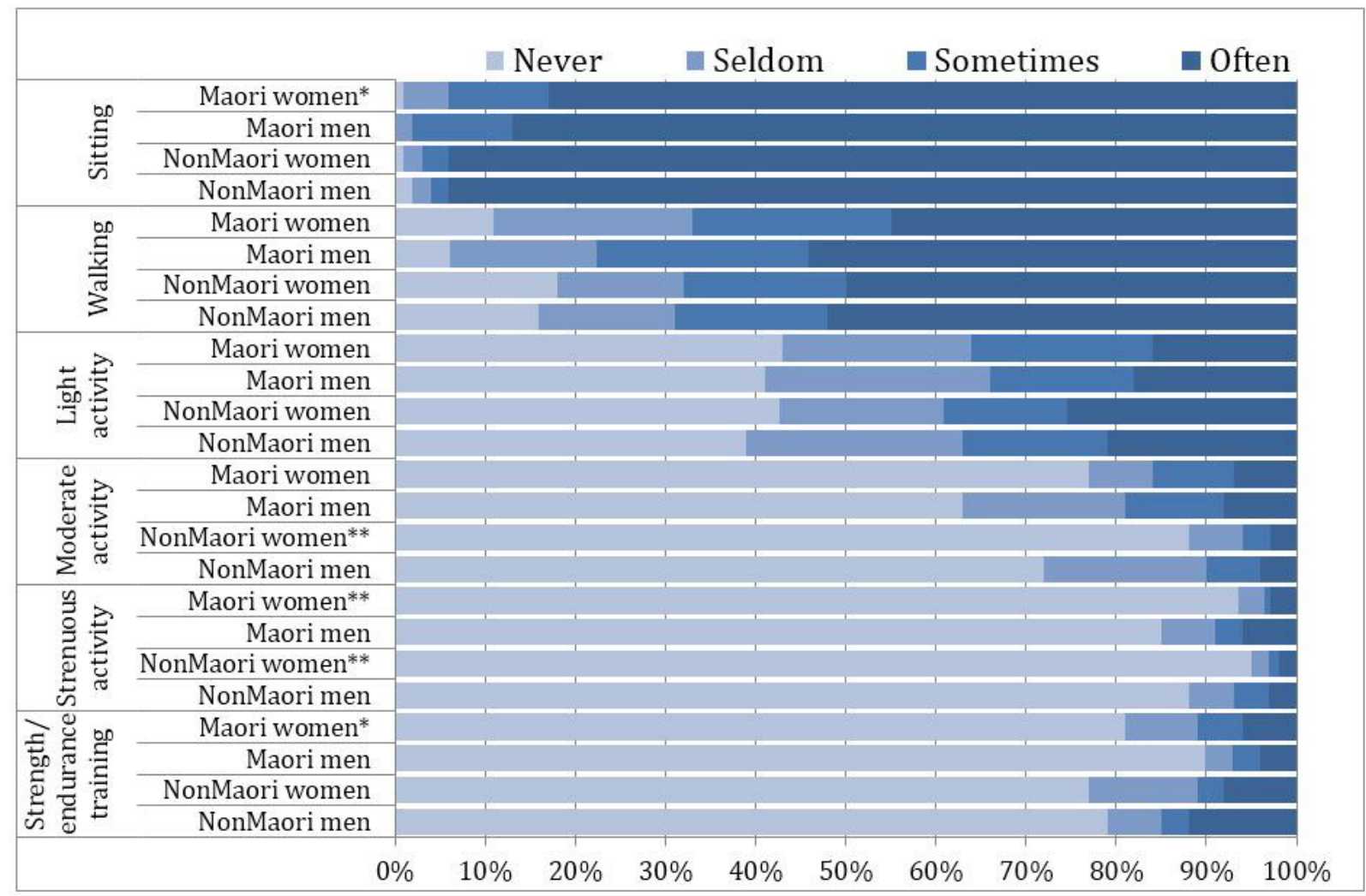

Figure 1 - Frequency of leisure-based activities (PASE). Note. $\% *=p<.05$ or $\% * *=p<.001$ on female percentages denote significant difference between men and women, measured by a construct of PASE (Physical Activity Scale for the Elderly).

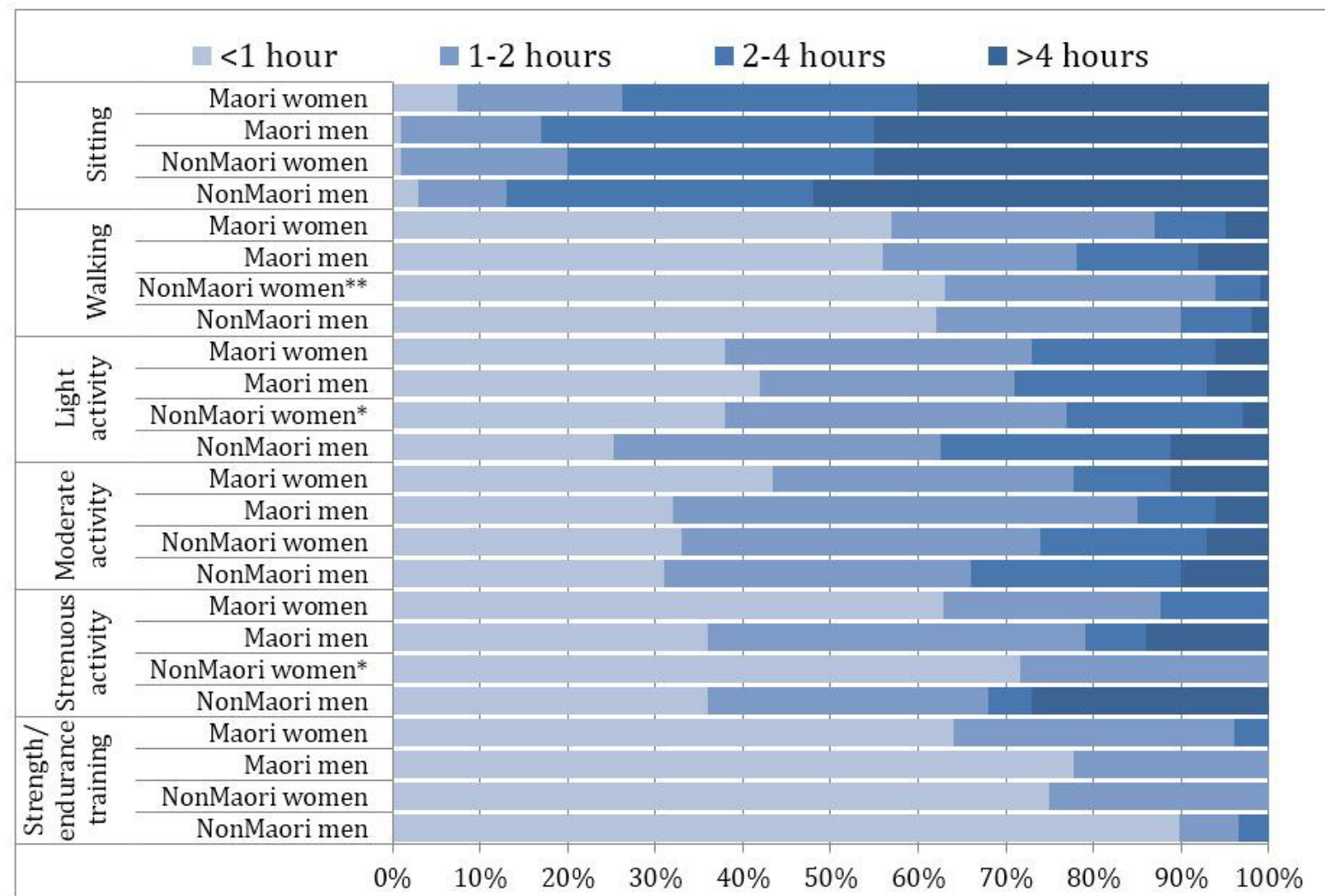

Figure 2 - Duration of leisure-based activities (Physical Activity Scale for the Elderly). Note: $* p<.05$ and $* * p<.001$ on women's variables for differences within Māori and Non-Māori sex analyses. 




Figure 3 - Men and women's accelerometer patterns during $24 \mathrm{hr}$ (average count per minute). *Graph displays 6:00 a.m.-12:00 a.m. NSPA > 100 counts per minute.

\begin{tabular}{|c|c|c|c|}
\hline & All $(n=45)$ & Men $(n=23)$ & Women $(n=22)$ \\
\hline Variable & Mean (SD) & Mean (SD) & Mean (SD) \\
\hline \multicolumn{4}{|l|}{ MARCA } \\
\hline *PAL (METs) daily average & $1.42(0.18)$ & $1.45(0.20)$ & $1.40(0.15)$ \\
\hline NSPA (min/day) daily average & $268.7(118.32)$ & $270.4(123.44)$ & $266.6(123.56)$ \\
\hline \multicolumn{4}{|l|}{ Accelerometer } \\
\hline Average daily activity counts & $129,234(82,488)$ & $130,141(81,559)$ & $128,397(83,918)$ \\
\hline Daily average activity count $\cdot \mathrm{min}^{-1}$ & $144.0(104.42)$ & $154.5(113.01)$ & $143.0(112.73)$ \\
\hline
\end{tabular}

Notes. MARCA = Multimedia Activity Recall for Children and Adults; PAL = physical activity level expressed by metabolic equivalent tasks (METs); NSPA = minutes spent in nonsedentary physical activity.

*Denotes significant difference between men and women at $p<.05$ level.

doing different activities. Men and women spent similar amounts of time tending to self-care. On average, women spent more time on instrumental activities of daily living $(+73 \mathrm{~min})(t[42]=5.831$, $p=.010)$ and on arts and crafts $(+30 \mathrm{~min})(t[10]=3.162, p<.001)$ than men. Men spent more daily average time on home maintenance activities $(+31 \mathrm{~min})(t[31]=-.4 .780, p<.001)$ and screen time $(+46$ $\min )(t[28]=-3.151, p<.001)$ per day than women. Men also spent more time walking $(+7 \mathrm{~min})(t[41]=-1.500, p<.001)$ and gardening $(+16 \mathrm{~min})(t[38]=-1.630, p=.010)$ than women. Contrasting time spent in activities was constrained by the small sample size (Table 4).

\section{Discussion}

Valuable insight into the type, duration, and frequency of physical activities performed by advanced age adults in New Zealand has been gained by this study. Further, this data addresses a substantial gap in the literature for the advanced age population. Overall, participants were modestly active, though it is difficult to make comparisons as this is the first study focused on an advanced age cohort.
However, this study did demonstrate patterns found in other research comparing activity levels in older men and women. Data from the PASE, MARCA, and accelerometers demonstrated that men consistently have higher levels of physical activity than women regardless of ethnicity even in advanced age, which is in agreement with previous research (Shephard, 1997). The Māori cohort had a younger average age than the non-Māori cohort, though when age was controlled there were no significant differences between activity levels for the groups.

Overall activity levels from the MARCA were consistent with previous literature, suggesting a general low level of activity among older adults (Nelson et al., 2007). When data were compared with previous MARCA validation samples, it was noted that the average physical activity level was 1.42 METs per day on average, which is lower than observed in children (1.87 METs) and adults (1.62 METs) (these estimates do not include diet-induced thermogenesis). One study $(n=302)$ measuring physical activity levels with doubly labeled water found that older adults had an average PAL of 1.70, ranging from 1.48 to -1.94 (Manini et al., 2006) and suggesting 


\section{Table 4 Average Time (Min) Spent in Activity Per Day by Sex as Reported by the MARCA and Minimum-Maximum}

\begin{tabular}{|c|c|c|c|}
\hline & Men $(n=24)$ & Women $(n=24)$ & \\
\hline Activity & Mean (SD) Min-Max & Mean (SD) Min-Max & $T$-Test Results, $t(p)$ \\
\hline Sleep & 581.0 (79.1) 420-780 & 578.2 (83.7) 390-800 & $(t=-.240, p=.340)$ \\
\hline Sit & 589.0 (86.8) 335-845 & 590.0 (94.2) 225-865 & $(t=.189, p=.445)$ \\
\hline Sitting quietly & 25.5 (45.1) 0-180 & $31.1(54.6) 0-240$ & $(t=.770, p=.144)$ \\
\hline Reading/writing & 114.6 (113.9) 0-420 & 111.2 (118.6) 0-590 & $(t=-.203, p=.561)$ \\
\hline TV/movies* & 210.29 (116.2) 0-515 & 164.7 (82.6) $0-475$ & $(t=-3.151, p<.001)$ \\
\hline Arts/crafts sitting* & $7.6(29.2) 0-225$ & $37.6(85.2) 0-390$ & $(t=3.162, p<.001)$ \\
\hline Puzzle (e.g., crossword)* & 14.0 (32.2) $0-130$ & $26.2(61.4) 0-315$ & $(t=1.680, p<.001)$ \\
\hline Listening to music sitting & $9.6(30.9) 0-155$ & 9.5 (34.9) 0-185 & $(t=-.001, p=.910)$ \\
\hline Spiritual activities* & $1.2(8.2) 0-60$ & 11.9 (41.5) 0-250 & $(t=2.381, p<.001)$ \\
\hline Social sitting & $84.2(90.0) 0-435$ & 91.7 (90.2) 0-440 & $(t=.730, p=.580)$ \\
\hline ADL sitting & 97.0 (39.7) 50-305 & 92.6 (36.1) 25-225 & $(t=-.701, p=.581)$ \\
\hline Occupation/working sitting* & 25.0 (64.9) $0-430$ & $13.1(39.8) 0-240$ & $(t=1.503, p=.010)$ \\
\hline Move & 270.3 (113.2) 75-530 & 270.9 (121.2) 25-625 & $(t=.102, p=.690)$ \\
\hline $\mathrm{ADL}$ & 41.0 (19.5) 0-95 & 35.2 (18.7) 0-70 & $(t=-2.111, p=.663)$ \\
\hline IADL* & 85.6 (74.0) $0-410$ & 158.6 (94.4) 0-410 & $(t=5.831, p=.010)$ \\
\hline Home maintenance* & $33.8(66.2) 0-330$ & $2.0(13.2) 0-120$ & $(t=-.4 .780, p<.001)$ \\
\hline Walking* & $21.1(32.4) 0-190$ & 15.5 (17.98) 0-60 & $(t=-1.500, p<.001)$ \\
\hline Gardening* & 57.4 (74.9) 0-385 & $41.4(61.1) 0-275$ & $(t=-1.630, p=.010)$ \\
\hline Recreation* & $15.2(52.8) 0-230$ & 7.3 (35.5) 0-240 & $(t=-1.240, p=.010)$ \\
\hline Exercise & $2.6(10.7) 0-85$ & $3.8(14.0) 0-70$ & $(t=.660, p=.150)$ \\
\hline Arts/crafts standing & 2.0 (11.8) 0-90 & 2.6 (15.6) $0-105$ & $(t=.301, p=.500)$ \\
\hline Work/study* & $8.4(41.2) 0-340$ & 1.3 (11.5) 0-115 & $(t=-1.663, p<.001)$ \\
\hline
\end{tabular}

MARCA = Multimedia Activity Recall for Children and Adults; ADL = activities of daily living; IADL = instrumental activities of daily living.

Note. Activities with average time $<1$ min not included in table.

*Indicates significant time difference in activity between men and women.

PAL observed in the current study may be reasonably accurate. Although the WHO has classified physical activity levels (METs) for adults (sedentary $=1.40-1.69$, active $=1.70-1.99$, vigorous activity $=2.00-2.40$ ), there are no norms for those in advanced age, and it is probable that a lower MET threshold for 'active' is needed for those in advanced age. (Manini et al., 2006; Starling, Matthews, Ades, \& Poehlman, 1999).

Women in the main and substudy were engaged in higher levels of household chores or housework than men. Men in the main study and substudy had higher levels of home maintenance than women. The non-Māori women in the main study had higher levels of occupational activity, but in the substudy non-Māori men had higher levels of occupational activity. Walking and gardening were important to both sex and ethnic groups. However, the MARCA and PASE found some differences in reported activities. For example, the MARCA demonstrated that men spent more time in occupational activities, but the PASE demonstrated that more women reported engaging in occupational activity. These are interesting details. As the PASE was conducted on the whole group, it is potentially more generalizable, as the subgroup had lower levels of disability and a different sex balance. However, the MARCA allows for more specific detailed reporting than the PASE in terms of smaller units of time, effort exerted, and the specific activity which was undertaken.
In each study, between a quarter to half of advanced age adults reported participating in work, most of which is volunteer activity. Nearly half of non-Māori women and around a third of non-Māori men participated in volunteer work. Volunteer activities provide opportunity for civic engagement, socializing, and maintaining an active lifestyle.

For Māori in New Zealand and especially those of older age, tribal as well as community involvement is important and includes regular participation in cultural activities and events. These Māori cultural activities and events are not classified as 'work' by Māori; the roles and responsibilities are essential to being Māori. Māori of older age are often called upon to conduct the cultural rituals involved in these activities and events. Their participation maintains and enhances their prestige, authority, control, and connection to their tribal land and kin relations, simultaneously passing on mātauranga Māori (Māori knowledge) to younger generations. Māori language and culture are pivotal to a healthy life (Kāpa et al., 2014).

In addition to their cultural roles and responsibilities, 23-31\% of the Māori women and men engaged in some form of work, most of which was volunteer based. The PASE did not allow for a distinction of these activities; though the MARCA has the ability to assess time in spiritual activities, time spent in cultural activities was 
not aggregated. The MARCA may have potential to differentiate these activities in the future. However, time measurement is also a Western scientific construct and may have limitations in measuring Māori populations, as time is not thought of in terms of minutes and hours; rather, time is understood as space and relations (Smith, 1999; Waldon, 2003).

According to the MARCA, older men and women spend their time engaged in a variety of activities. The range of time spent in each category of activity varies considerably, although approximately the same amount of time is spent sleeping, being active, and being sedentary. Women spent more time engaged in IADLs, which includes the entire range of housework chores (vacuuming, dusting, dishes) but also includes other activities associated with independent living such as driving and managing finances. Men engaged in more home maintenance activities, including chopping wood, cleaning gutters, plumbing, and fixing things, which was also found by the PASE. It is unlikely that women require more time to complete IADLs or men require more time to complete home maintenance due to the nature of the activities, it is more likely that this is due to gender role patterns that have been demonstrated in previous research conducted on younger old adults (Shephard, 2002). All older adults reported doing some form of ADL self-care which is associated with independent living, however some did not report any time engaged in standing ADLs, but only while sitting. Individuals who cannot or do not stand while performing self-care activities may be experiencing lower physical function or some form of disability.

Overall, men reached higher accelerometer count per minute thresholds and their daily activity pattern could be described as having a bout of higher intensity activity in the morning and a smaller, less intense period of activity in the afternoon. Women maintained an overall lower intensity of activity but maintained longer periods of steady activity. These differences in daily activity patterns between men and women have also been previously observed in other populations of adults and younger old adults (Davis \& Fox, 2007). Although there are very few studies specifically using accelerometer measures of activity in advanced age individuals, there is evidence that it is still a useful measure for older people. Another study that included samples of 80-85-year-olds found that there was not a significant difference between men and women for accelerometer counts per minute, however the sample of octogenarians was small $(n=65)$. The patterns of accelerometer counts per minute were 150-160 on average, which was a bit higher than this study, which was expected given the lower average age of the sample. (Hansen, Ommundsen, Holme, Kolle, \& Anderssen, 2014).

In the substudy there was substantial variation in the time spent undertaking particular activities. Some participants reported only sleeping $6.5 \mathrm{hr}$ per day while others reported sleeping up to 13 hr per day. However, this sleep included daytime napping, which was reported as either planned, laying down for a rest, or occurred during an activity such as reading. Advanced aged adults were physically active during $19 \%$ of their day and most of this activity was comprised of daily housework, home maintenance, gardening, or walking. Little time was spent in purposive exercise and sport and recreation comprised a small amount of time relative to other physical activities. The most common sedentary behaviors included reading, watching television, puzzling, crafting, socializing, working, or just sitting quietly. Men in particular reported a substantial amount of time (over $3 \mathrm{hr}$ per day) on average watching television, while women watched about $2.5 \mathrm{hr}$.

Given the risks associated with sedentary behavior, this issue could be researched further. Also, socializing is an important part of an older adult's day, comprising at least $1 \mathrm{hr}$ to $1.5 \mathrm{hr}$ each day.
Social activity is an important part of healthy aging and determining sufficient levels of socializing is imperative in any successful aging regimen. These details could only be derived from the MARCA, as the PASE provides very broad categories of activity. Information from the MARCA could be key in developing specific interventions to increase a particular time spent in an activity or to increase participation in a specific activity.

\section{Strengths and Limitations}

A key strength of this study was being able to analyze physical activity in people in advanced age using various measures. Having a widely-used self-report measure of physical activity (PASE) as well as a self-report measure thought to provide more precise detail (MARCA) along with the objective accelerometer monitoring provided a substantial amount of information. This PASE study benefitted from a relatively large sample number so that each population of men and women and Māori and non-Māori could be examined, making the results more relevant to each population. However, separating the groups was also limiting because it meant smaller sample sizes. Performing multiple $T$-tests can introduce type I error; however, given the exploratory and novel nature of this study, it was important not to miss important leads found by this data (Rothman, 1990). Therefore, future studies may want to perform alternative statistical analyses based upon these findings.

The exhaustive sampling technique for the LiLACS NZ study allowed for as many participants as possible. The measures in this study were all the most generally accepted measures; therefore, from a scientific critique, the findings are valid and reliable. However a major limitation is that the Western scientific measures do not account for an alternate worldview and therefore Māori in the study are not fully able to validate their activity in a way that is meaningful to them. Ethical considerations involved in this study meant that Māori and non-Māori were analyzed separately so that the results would be relevant to each population. To respect and understand issues that are important to Māori, it is important to provide data that can be interpreted and used by the Māori community. This was viewed as a strength by the research team, as it was a successful cross-cultural collaboration.

The subsample was derived from a larger cohort study and was limited by the constraints of that particular cohort. One benefit of sampling from the cohort participants is that it allowed controlling the sample for cognitive impairment through a valid screening process (3MSE). However, the sample size was small $(n=45)$, and including only older community-dwelling adults without cognitive impairment does not accurately reflect the spectrum of older adult populations. Community dwelling is associated with independence, which is related to higher levels of physical activity (Salguero, Martínez-García, Molinero, \& Márquez, 2011). Therefore, this sample is most likely a more active segment of the population and it is not clear whether this measure would be appropriate for older adults in institutional settings.

We also used an objective measure of physical activity to provide a comparative measure of activity levels. Using accelerometers to assess physical activity and sedentary behavior in those of advanced age presents some unique challenges. Variation in health status and physical fitness is greatest among older people (Luke, Dugas, Durazo-Arvizu, Cao, \& Cooper, 2011). Because of the multidimensional biological and environmental factors of aging it is difficult to identify robust accelerometer activity cut point thresholds that are relevant across the spectrum of older people (Matthews, Ainsworth, Thompson, \& Bassett Jr., 2002; Miller, Strath, Swartz, \& Cashin, 2010). Aside from implementing accelerometers in 
older persons, there are also several challenges in interpreting and categorizing accelerometer data in older people. Finally, a limitation of the MARCA is that the MET values associated with each activity are derived from the adult compendium (Ainsworth et al., 2000). However, for any given activity (e.g., vacuuming) the MET value for people of advanced age is likely to be lower than for a younger adult (from whom the compendium data were obtained). The compendium is frequently updated and the MARCA has the capability to be easily updated as information comes available. In the meantime, we suggest that nonsedentary activity is a valid and reliable activity to examine in detail.

\section{Implications}

As with other use-of-time instruments, the MARCA provides important information beyond moderate-to-vigorous physical activity levels. While it is recognized that moderate-to-vigorous physical activity is beneficial for a variety of mental and physical health outcomes, recent literature for older adults indicates that time spent being active rather than achieving specific intensity levels (Salguero et al., 2010) has health benefits. Furthermore, sedentary behavior as a risk factor for age-related morbidities and mortality among older adults has recently been examined (Conn, Hafdahl, \& Brown, 2009; Nelson et al., 2007; Salguero et al., 2011). Future studies can build physical activity interventions for advanced aged adults with this information. Increasing time spent in physical activities, or time spent in more intense activities, could be a potential target for future interventions. Using the MARCA to track overall increases in PAL is also a potentially useful undertaking. Overall, determining the causes of spending less time in physical activity as one ages is an important area of research for the future, even in advanced aged people.

\section{Conclusion}

This study has provided novel, descriptive data about the activities in which advanced aged people engage and how they spend their time. This study has also provided data that can be compared and collated with larger data sets concerning physical activity levels in older age. Advanced aged people spend a good deal of time engaged in household activities and leisure activity, and quite a number of older people engage in regular volunteer work. Activity levels and the intricacies of the behaviors differed by sex for both Māori and non-Māori population.

\section{References}

Ainsworth, B., Haskell, W., Whitt, M., Irwin, M., Swartz, A.M., Strath, S.J., . . . Emplaincourt, P.O. (2000). Compendium of physical activities: an update of activity codes and MET intensities. Medicine and Science in Sports and Exercise, 32(9, Suppl.) S498. PubMed doi:10.1097/00005768-200009001-00009

Annear, M.J. (2008). They're not including us!": neighbourhood deprivation and older adults' leisure time physical activity participation. (Masters Science Masters). Christchurch, New Zealand: Lincoln University., Retrieved from http://researcharchive.lincoln.ac.nz/ dspace/handle/10182/468.

Banda, J.A., Hutto, B., Feeney, A., Pfeiffer, K.A., Mc, I.V.E.R., La, K., . . . Hooker, S.P. (2010). Comparing physical activity measures in a diverse group of midlife and older adults. Medicine and Science in Sports and Exercise, 42(12), 2251. PubMed doi:10.1249/ MSS.0b013e3181e32e9a
Conn, V.S., Hafdahl, A.R., \& Brown, L.M. (2009). Meta-analysis of quality-of-life outcomes from physical activity interventions. Nursing Research, 58(3), 175. PubMed doi:10.1097/NNR.0b013e318199b53a

Davis, M.G., \& Fox, K.R. (2007). Physical activity patterns assessed by accelerometry in older people. European Journal of Applied Physiology, 100(5), 581-589. PubMed doi:10.1007/s00421-006-0320-8

de Craen, A.J.M., Heeren, T., \& Gussekloo, J. (2003). Accuracy of the 15 -item geriatric depression scale (GDS-15) in a community sample of the oldest old. International Journal of Geriatric Psychiatry, 18(1), 63-66. PubMed doi:10.1002/gps.773

Dyall, L., Kepa, M., Hayman, K., Teh, R., Moyes, S., Broad, J.B., \& Kerse, N. (2013). Engagement and recruitment of Māori and non-Māori people of advanced age to LiLACS NZ. Australian and New Zealand Journal of Public Health, 37(2), 124-131. PubMed doi:10.1111/17536405.12029

Gomersall, S.R., Olds, T.S., \& Ridley, K. (2011). Development and evaluation of an adult use-of-time instrument with an energy expenditure focus. Journal of Science and Medicine in Sport, 14(2), 143-148. PubMed doi:10.1016/j.jsams.2010.08.006

Hansen, B.H., Ommundsen, Y., Holme, I., Kolle, E., \& Anderssen, S.A. (2014). Correlates of objectively measured physical activity in adults and older people: a cross-sectional study of population-based sample of adults and older people living in Norway. International Journal of Public Health, 59(2), 221-230. PubMed doi:10.1007/s00038-0130472-3

Harada, N., Chiu, V., King, A., \& Stewart, A. (2001). An evaluation of three self-report physical activity instruments for older adults. Medicine and Science in Sports and Exercise, 33(6), 962. PubMed doi:10.1097/00005768-200106000-00016

Hayman, K.J., Kerse, N., Dyall, L., Kepa, M., Teh, R., Wham, C., . . . Connolly, M.J. (2012). Life and living in advanced age: A cohort study in New Zealand-Te Puawaitanga o Nga Tapuwae Kia Ora Tonu, LiLACS NZ: Study protocol. BMC Geriatrics, 12(1), 33. PubMed doi:10.1186/1471-2318-12-33

Kempen, G., Myers, A., \& Powell, L. (1995). Hierarchical structure in ADL and IADL: analytical assumptions and applications for clinicians and researchers. Journal of Clinical Epidemiology, 48(11), 1299-1305. PubMed doi:10.1016/0895-4356(95)00043-7

Kepa, M., Kepa, C.A., McPherson, B., Kameta, H., Kameta, K., Port, W., . . Reynolds, L. (2014). E kore e ngaro nga kakano i ruia mai i Rangiatea: The language and culture from Rangiatea will never be lost in health and ageing research. ALTERNATIVE, 10(3), 266-287.

Luke, A., Dugas, L., Durazo-Arvizu, R., Cao, G., \& Cooper, R. (2011). Assessing physical activity and its relationship to cardiovascular risk factors: NHANES 2003-2006. BMC Public Health, 11(1), 387. PubMed doi:10.1186/1471-2458-11-387

Mace, C., Maddison, R., Olds, T., \& Kerse, N. (2014). Validation of a computerized use of time recall for activity measurement in advanced aged adults. Journal of Aging and Physical Activity, 22, .245-254. PubMed

Manini, T.M., Everhart, J.E., Patel, K.V., Schoeller, D.A., Colbert, L.H., Visser, M., .. . Harris, T.B. (2006). Daily activity energy expenditure and mortality among older adults. Journal of the American Medical Association, 296(2), 171-179. PubMed doi:10.1001/jama.296.2.171

Marc, L.G., Raue, P.J., \& Bruce, M.L. (2008). Screening performance of the geriatric depression scale (GDS-15) in a diverse elderly home care population. The American Journal of Geriatric Psychiatry, 16(11), 914. PubMed doi:10.1097/JGP.0b013e318186bd67

Mâsse, L.C., Ainsworth, B.E., Tortolero, S., Levin, S., Fulton, J.E., Henderson, K.A., \& Mayo, K. (1998). Measuring physical activity in midlife, older, and minority women: issues from an expert panel. Journal of Women's Health, 7(1), 57-67. PubMed doi:10.1089/jwh.1998.7.57

Matthews, C.E., Ainsworth, B.E., Thompson, R.W., \& Bassett, D.R., Jr. (2002). Sources of variance in daily physical activity levels as measured by an accelerometer. Medicine and Science in Sports and Exercise, 34(8), 1376. PubMed doi:10.1097/00005768-200208000-00021

Miller, N., Strath, S., Swartz, A., \& Cashin, S. (2010). Estimating absolute and relative physical activity intensity across age via accelerometry in adults. Journal of Aging and Physical Activity, 18(2), 158. PubMed 
Nelson, M., Rejeski, W., Blair, S., Duncan, P., Judge, J., King, A., . . . Castaneda-Sceppa, C. (2007). Physical activity and public health in older adults. Recommendation from the American College of Sports Medicine and the American Heart Association. Circulation, 116, 1094-1105. PubMed

Nouri, F., \& Lincoln, N. (1987). An extended activities of daily living scale for stroke patients. Clinical Rehabilitation, 1(4), 301-305. doi:10.1177/026921558700100409

NZMOH. (2013). Guidelines to help older New Zealanders stay healthy. Wellington, New Zealand: Ministry of Health Retrieved from http:// www.health.govt.nz/news-media/media-releases/guidelines-helpolder-new-zealanders-stay-healthy.

Rejeski, W., \& Mihalko, S. (2001). Physical activity and quality of life in older adults. The Journals of Gerontology. Series A, Biological Sciences and Medical Sciences, 56(Suppl. 2), 23. PubMed doi:10.1093/ gerona/56.suppl_2.23

Ridley, K., Ainsworth, B.E., \& Olds, T.S. (2008). Development of a compendium of energy expenditures for youth. International Journal Behavior Nutrition Physical Activity, 5, 45.

Rothman, K.J. (1990). No adjustments are needed for multiple comparisons. Epidemiology (Cambridge, Mass.), 1(1), 43-46. PubMed doi:10.1097/00001648-199001000-00010

Salguero, A., Martínez-García, R., Molinero, O., \& Márquez, S. (2011). Physical activity, quality of life and symptoms of depression in community-dwelling and institutionalized older adults. Archives of Gerontology and Geriatrics, 53, 152-157. PubMed

Shephard, R.J. (1997). Aging, physical activity, and health. Champaign, IL: Human Kinetics Publishers.

Shephard, R.J. (2002). Gender, physical activity, and aging. Boca Raton, FL: CRC Press.
Smith, L.T. (1999). Decolonising Methodologies: Research and Indigenous Peoples London. London, UK: Zed Books Ltd.

SPARC. (2007/2008). Sport, Recreation, and Physical Activity Participation Among New Zealand Adults. Auckland, New Zealand: Active New Zealand Survey Retrieved from http://www.sportnz.org.nz/managingsport/research/active-new-zealand-survey-200709.

Sport and Recreation New Zealand. (2008). The Active-NZ Survey. Wellington: Sport and Recreation New Zealand.

Starling, R.D., Matthews, D.E., Ades, P.A., \& Poehlman, E.T. (1999). Assessment of physical activity in older individuals: a doubly labeled water study. Journal of Applied Physiology, 86(6), 2090-2096. PubMed

Teh, R., Kerse, N., Kepa, M., Doughty, R., Wham, C., Hayman, K., Wilkinson, T., Connolly, M., Dyall, L., Mace, C. (2014). Self-Rated Health, Health Related Behaviours and Medical Conditions of Māori and Non-Māori in Advanced Age: Lilacs NZ. NZ Medical Journal.

Tobias, M.I., \& Cheung, J. (2003). Monitoring health inequalities: life expectancy and small area deprivation in New Zealand. Population Health Metrics, 1(1), 2-14. PubMed

Waldon, J. (2003). Oranga Kaumātua: perceptions of health in older Māori people. Pacific Health Dialog, 10(2), 79-86. PubMed

Washburn, R.A., Smith, K.W., Jette, A.M., \& Janney, C.A. (1993). The physical activity scale for the elderly (PASE): development and evaluation. Journal of Clinical Epidemiology, 46(2), 153-162. PubMed doi:10.1016/0895-4356(93)90053-4

World Health Organization (WHO). (2009). Global Strategy on Diet, Physical Activity and Health: Physical Activity and Older Adults. Geneva, Switzerland: World Health Organisation Retrieved from http://whqlibdoc.who.int/publications/2010/9789241599979_eng. pdf. 
Copyright of Journal of Aging \& Physical Activity is the property of Human Kinetics Publishers, Inc. and its content may not be copied or emailed to multiple sites or posted to a listserv without the copyright holder's express written permission. However, users may print, download, or email articles for individual use. 